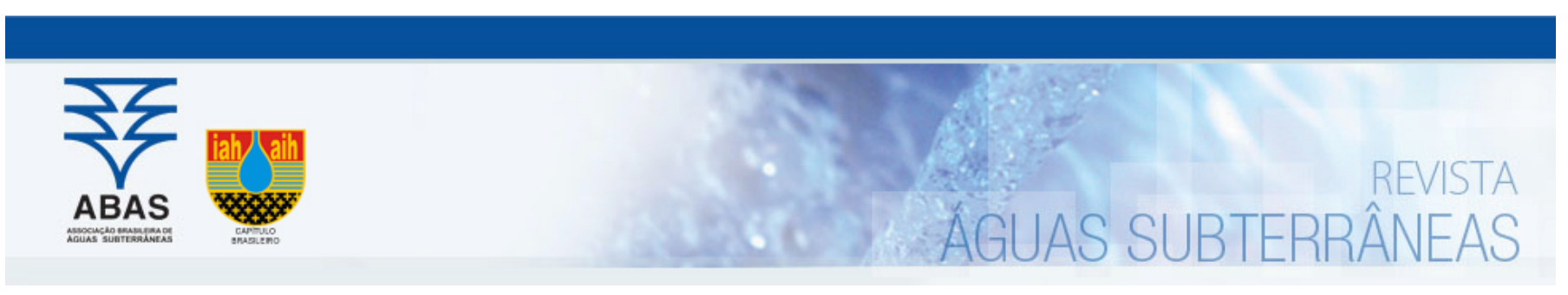

Artigos

\title{
Qualidade físico-química da água para abastecimento humano em municípios do sertão da Bahia: um estudo considerando diversas fontes de suprimento
}

\author{
Physical-chemical quality of water for human municipalities of the sertão da \\ Bahia: a study considering several sources of supply
}

\author{
Lidiane Mendes Kruschewsky Lordelo1; José Milton Porsani 2; Patrícia Campos Borja $2 \bowtie$ \\ 1 Universidade Federal do Recôncavo da Bahia (UFRB), Cruz das Almas, BA \\ 2 Universidade Federal da Bahia (UFBA), Salvador, BA \\ \lidianelordelo@yahoo.com.br, milton.porsani@gmail.com, borja@ufba.br
}

Resumo

Palavras-chave:

P1MC.

Cisternas.

Método Piper.

O abastecimento de água nas áreas rurais do sertão brasileiro é dificultado devido à escassez de água e adoção de políticas e tecnologias inapropriadas que envolvem desde a captação até a distribuição ao consumidor. Atualmente, diversas são as fontes utilizadas para o suprimento de água, tais como: águas subterrâneas (poços), água de chuva (cisterna), e águas superficiais, o que inclui água do carro-pipa. Diante da necessidade de se garantir o acesso à água em face da sua importância para a promoção da saúde, o presente estudo visou analisar a qualidade das águas disponíveis para consumo humano, quanto aos parâmetros físico-químicos, provenientes das fontes citadas em cinco municípios do semiárido baiano. Os resultados evidenciaram que as condições áridas do solo influenciam na qualidade da água dos poços da região estudada tornando-as mais salobras. Por outro lado, as águas provenientes de carro-pipa que abastecem as cisternas do P1MC em face da seca prolongada estavam vulneráveis devido ao uso do cloro sem o devido controle podendo estar acima do permitido. As águas de chuva apresentaram condições adequadas quanto às características físico-químicas. Os resultados indicam a necessidade de políticas públicas que garantam o acesso à água de qualidade na região estudada.

\section{Abstract}

Keywords:

P1MC.

Cisterns.

Piper Method.

Revisado por pares.

Recebido em: 07/07/2017.

Aprovado em: 16/02/2018.

\begin{abstract}
Water supply in rural areas of the Brazilian hinterland is hampered by water shortages and inappropriate policies and technologies that range from capture to distribution to the consumer Currently, several sources are used for water supply, such as: groundwater (wells), rainwater (cistern), and surface water, which includes water from the car-kite. In view of the need to guarantee access to water due to its importance for health promotion, the present study aimed to analyze the quality of the water available for human consumption, in terms of physical and chemical parameters, from the sources mentioned in five municipalities of the Semiarid region of Bahia. The results showed that the arid soil conditions influence the water quality of the wells of the studied region, making them more brackish. On the other hand, water from a car-kite that supplies P1MC cisterns in the face of prolonged drought was vulnerable due to the use of chlorine without proper control and may be above permitted. The rainwater presented adequate conditions about physico-chemical characteristics. The results indicate the need for public policies that guarantee access to quality water in the region studied.
\end{abstract}

DOI: $\underline{\text { http://dx.doi.org/10.14295/ras.v32i1.28896 }}$

\section{INTRODUÇÃO}

O semiárido brasileiro ocupa uma área entre 750.000 a $850.000 \mathrm{~km}^{2}$, equivalendo a $48 \%$ da área total da região Nordeste e $10 \%$ do território nacional. Uma das maiores e mais populosas regiões semiáridas do mundo, habitam nessa região mais de dezoito milhões de pessoas, sendo oito milhões na área rural. (MELO FILHO; SOUZA, 2006). 57\% do estado da Bahia encontra-se na zona semiárida brasileira. São 254 municípios, sendo 126 totalmente e 128 parcialmente ocupando uma área de $320.211 \mathrm{~km}^{2}$ (BARBOSA, 2000).

O semiárido brasileiro apresenta reservas de água insuficientes em seus mananciais, temperaturas elevadas em todos os meses do ano, baixas amplitudes térmicas, forte insolação e alta taxa de evapotranspiração. Os totais pluviométricos são irregulares e variam, dependendo do município, apresentando médias pluviométricas entre 300mm a 1.300mm (RAMALHO, 2013). 
Segundo Brasil (1999), citado posteriormente por Melo Filho e Souza (2006) 78\% das águas precipitadas são consumidas pela evapotranspiração; 15\% pelo escoamento superficial e 7\% pela infiltração e escoamento subterrâneo. Para os autores, todo o volume precipitado concentra-se apenas entre dois a quatro meses do ano, o que dificulta o processo do armazenamento superficial de água, infiltração e captura dessa água pelas raízes das plantas.

Avaliando a precipitação associada ao escoamento superficial e infiltração, pode-se perceber que as etapas do ciclo hidrológico não contribuem para permanência da água no local da precipitação. 0 tipo de solo existente nas áreas áridas e semiáridas dificulta a infiltração. A quantidade de água precipitada é grande em um pequeno intervalo de tempo, contribuindo para intemperismo físico, lixiviação do solo e perda da camada orgânica. Segundo Melo Filho e Souza (2006), “(...) o período úmido as chuvas apresenta elevada intensidade que associada ao significativo escorrimento superficial contribuem acentuadamente para reduzir o aproveitamento da água" (p. 52).

As características meteorológicas do nordeste brasileiro, precipitação condensada em uma pequena quantidade de meses, com grande intensidade e seca prolongada, segundo Molion e Bernardo (2000) decorrem da sua localização (adjacência a região Amazônica), local onde são ocorrem os movimentos convectivos amplos e intensos.

Os recursos hídricos subterrâneos são representados pelas águas da bacia Tucana (Tucano-Jatobá), na divisa da Bahia com Pernambuco. Devido a $70 \%$ do subsolo ser cristalino na região Nordeste, com vários pontos de área sedimentar, existe um potencial significativo de exploração dessas águas para o abastecimento local (BRITO; PREREIRA; MELO, 2009). Ainda segundo os autores, as rochas cristalinas no subsolo contribuem para que as águas subterrâneas sejam salobras e salinas, dificultando seu aproveitamento para consumo humano. Essas águas, mesmo apresentando teores de sólidos dissolvidos totais, e predominância de cloretos, têm uma importante contribuição para o abastecimento das famílias, que em diversas situações não dispõem de outras fontes de abastecimento humano, dessedentação de animais e irrigação. A ocorrência de solos salinos é comum na caatinga, pois há baixa precipitação e alta taxa de evaporação. Sendo assim, os sais não lixiviados acumulam-se na zona radicular em concentrações prejudiciais ao crescimento normal das plantas. Entretanto, a salinidade induzida ocorre em decorrência da irrigação praticada nessas áreas onde o controle da drenagem não é feito ou é feito de forma ineficiente. Os métodos de controlar ou amenizar os níveis de salinidade altos utilizados são o uso do sistema de drenagem dos solos, sistema de irrigação correta e frequente para a lavagem e utilização de plantas halófitas que sequestram os sais do solo (OLIVEIRA, 1997).

É nesse cenário, característico do sertão da Bahia e situado na parte norte/nordeste do estado, que se localizam os municípios de Abaré, Chorrochó, Macururé, Glória e Santa Brígida objeto do presente estudo. Sendo o estudo de Lordelo et al. (2015), a partir da classificação de Thornthwaite (1948), a área estudada é árida. Como já foi exposto, a região que tem como características ambientais chuvas escassas e irregulares, sendo no período de ocorrência caracterizada por trombas d'águas (grande volume em pouco tempo de precipitação), com períodos de estiagem extensos e secas prolongadas. Essas características ilustram a realidade existente no sertão, com valores deficitários de volume de água, contribuindo para as dificuldades enfrentadas quando se analisa as possibilidades do uso da água e da terra.

Devido às condições naturais do sertão serem adversas, a disponibilidade hídrica para o abastecimento de água não é favorável, faltando ou inexistindo água durante meses do ano. Assim, o serviço de abastecimento de água para as famílias que residem na zona rural do sertão brasileiro sempre foi um desafio para os governantes e empresas prestadoras dos serviços de abastecimento. As águas superficiais são escassas, com a maior parte dos rios apresentando regime intermitente, e as águas subterrâneas não dispõem de vazão suficiente e qualidade adequada para o abastecimento e, além disso as precipitações pluviométricas são baixas.

Diante da problemática existente no sertão brasileiro, e no anseio de solucionar o abastecimento de água para consumo humano, no início dos anos 2000, a Articulação no Semiárido Brasileiro (ASA), entidade que agrega mais de 3 mil organizações da sociedade civil e que trabalha para o desenvolvimento social, econômico, político e cultural do semiárido, desenvolveu o Programa Um Milhão de Cisternas (P1MC), que envolveu, além de outros objetivos, a construção de cisternas para coleta e armazenamento de água pluvial. A elaboração do P1MC se baseou em experiências de organizações da sociedade civil que trabalharam no semiárido com a construção de cisternas de placas. O P1MC foi planejado dentro de uma ótica de participação popular, envolvendo o maior número possível de atores. Em 2003, esse Programa foi incorporado às ações do Governo Federal por meio do Programa Acesso à Alimentação do então Ministério do Desenvolvimento Social e Combate à Fome (MDSCF). Segundo dados da ASA até o junho de 2017 foram construídas um total de 602.003 cisternas (ASA, 2002; ASA, 2017).

As alternativas que vêm sendo utilizadas para suprimento de água da região envolvem o uso de carro-pipa, rede de distribuição, poço e captação de água de chuva. Porém essas águas são distribuídas diretamente para a população, na sua maioria, sem tratamento. Devido à água ser para consumo humano, no Brasil existem legislações e portarias que estabelecem padrões de qualidade da água que precisam ser atendidos. A Portaria $\mathrm{N}^{\circ}$ 2914/2011, do Ministério da Saúde, estabelece as normas e padrões de potabilidade e os procedimentos para o controle e de vigilância da qualidade da água para consumo humano. Apesar da Portaria privilegiar a regulação do fornecimento de água para os sistemas ou soluções coletivas, alguns artigos tratam das soluções individuais, onde os sistemas de captação e armazenamento de águas de chuva podem ser contemplados. A Resolução Conama No 396/2008 dispõe sobre a classificação e diretrizes ambientais para o enquadramento das águas subterrâneas e dá outras providências, mas não enquadra as águas subterrâneas em doce, salobra e salgada. Esse enquadramento só é visto na Resolução Conama № 357/2005. A classificação das águas dos aquíferos foi feita a partir da possível alteração de sua qualidade por atividades antrópicas, necessidade de tratamento para quaisquer usos preponderantes devido às suas características hidrogeoquímicas naturais, podendo ser enquadradas em classes especial, I, II, III, IV, e V. Na ausência de uma legislação que 
trate da salinidade da água subterrânea, foram desenvolvidos alguns métodos para esse fim.

Considerando a necessidade de garantir o acesso à água para consumo humano em quantidade e em qualidade no semiáriodo baiano, o objetivo deste trabalho é analisar a qualidade das águas disponíveis para tal fim, quanto aos parâmetros físico-químicos, as provenientes de poços, carro-pipa e água de chuva.

Este trabalho tem financiamento do Conselho Nacional de Desenvolvimento Científico e Tecnológico (CNPq). Os dados sobre a qualidade da água dos poços da região estudada foram gentilmente fornecidos pela Companhia de Engenharia Hídrica e de Saneamento da Bahia (CERB).

\section{METODOLOGIA}

A metodologia envolveu uma pesquisa de campo com coleta de dados primários nos municípios de Abaré, Chorrochó, Macururé, Glória e Santa Brígida (Figura 1), no Semiárido Baiano. A região de estudo foi selecionada considerando os seguintes critérios: situação de escassez hídrica (precipitação média anual menor que $600 \mathrm{~mm}$ ) e população do município (menor que 20.000 habitantes).

Figura 1 - Municípios estudados (Abaré, Chorrochó, Macururé, Glória e Santa Brígida)

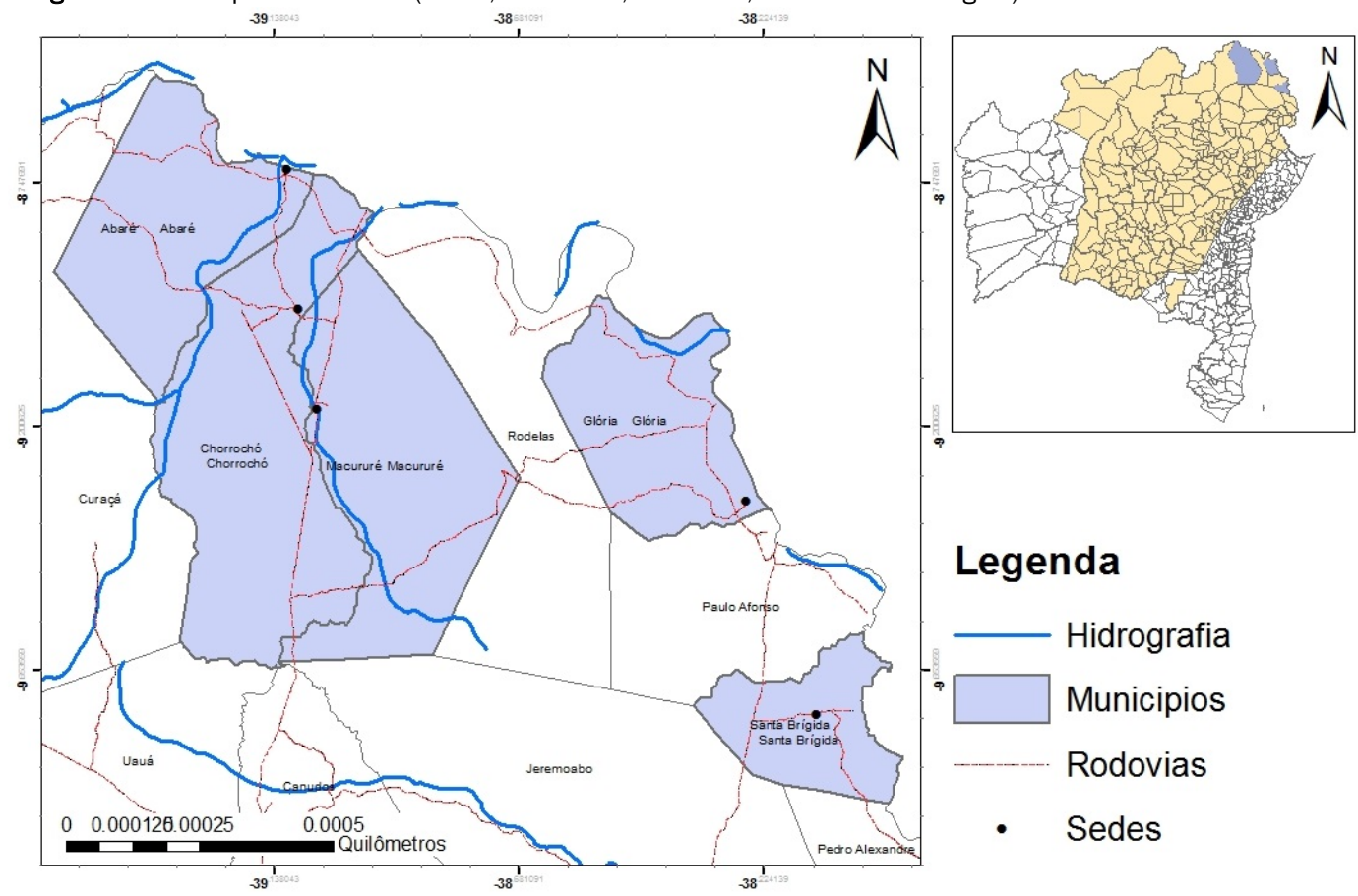

Fonte: IBGE (2017)

A partir de uma amostragem aleatória estratificada foram coletadas amostras de água nas cisternas de 455 domicílios, identificando-se a origem da água e analisando-se os parâmetros físicoquímicos e microbiológicos que determinam a potabilidade da água, segundo a Portaria № 2914/2011 do Ministério da Saúde.

Os parâmetros físico-químicos Dureza, Cloreto, Cor, Ferro, Amônia, Cloro e pH foram determinados por meio do Kit Técnico de Potabilidade. Ressalta-se que os referidos Kits demonstraram eficiência por meio do método Standard Methods for Examination of Water and Wastewater e são aprovados e registrados pelo Ministério da Saúde.

Os resultados foram enquadrados segundo os padrões de potabilidade estabelecidos pela Portaria $n^{\circ} 2914 / 2011$ do Ministério da Saúde quando a origem da água era de captação em rio ou água de chuva e proveniente de soluções alternativas individuais. No caso da origem ser de água subterrânea utilizou-se a Resolução Conama N 396/2008.
O estudo também envolveu a avaliação da qualidade da água dos poços perfurados pela Cerb nos municípios estudados e que são potenciais fontes de suprimento de água para consumo humano. Os dados foram fornecidos pela Cerb que detém uma base de dados significativa dos poços perfurados no estado da Bahia. A análise da qualidade das águas dos poços quanto à salinidade foi feita pelo método Piper (PIPER, 1944). 0 método Piper extrai de dois diagramas triangulares, os cátions principais $\left(\mathrm{Ca}^{+2}, \mathrm{Mg}^{+2}\right.$, $\mathrm{Na}^{+2} \mathrm{~K}^{+}$) e os ânions principais $\left(\mathrm{HCO}_{3}{ }^{-}, \mathrm{Cl}^{-} \mathrm{SO}_{4}^{-2}\right)$, que combinados geram informações que são dispostas em um losango situado entre os mesmos. Os pontos iônicos ocupam espaços no lado direito do losango que são classificados como águas cloradas sulfatada, cálcica ou magnesiana, águas bicarbonatadas, cálcicas ou magnesianas, águas cloretadas sódicas e águas bicarbonatadas sódicas. Quanto mais para o lado direito do losango o ponto se localizar, mais salgada é a água em estudo.

Após as análises das águas superficiais e subterrâneas foi feita a avaliação das possibilidades de abastecimento para cada município estudado. 


\section{RESULTADOS E DISCUSSÃO}

A pesquisa desenvolvida nos municípios de Abaré, Chorrochó, Macucuré, Glória e Santa Brígida, estudou as águas das cisternas do P1MC que abastecem essa população, tendo suas origens na água de chuva, as águas subterrâneas dos poços da Cerb e as águas superficiais captadas no rio São Francisco. Durante o levantamento de campo, foi detectada ausência de chuva durante grande período do ano e a intervenção do setor público para abastecer as cisterna com carro-pipa, a partir da captação da água, no rio São Francisco, em um ponto no município de IbóBA. Também detectou a presença de água de poços perfurados pela Cerb os municípios de Glória e Santa Brígida. Além disso, cerca de 54\% das cisternas em Glória eram abastecidas com carro-pipa e em Santa Brígida esse percentual foi de $32,76 \%$. No município de Glória, cerca de 14,75\% dos domicílios tinham suas cisternas abastecidas por água subterrânea de poços perfurados pela Cerb e em Santa Brígida chegou a 6,32\%. Nesse município um total de $44,83 \%$ das cisternas eram abastecidas com água de chuva, sendo que em Glória esse indicador era de 1,64\%. Análise da qualidade das águas das cisternas provenientes da captação de água de chuva e do abastecimento por meio de carropipa.

As águas das cisternas, que na sua maioria tem sua origem na captação superficial das águas do rio São Francisco, não têm tratamento antes do fornecimento realizado pelo carro-pipa. Porém, segundo dados coletados em campo, a população recebe uma pastilha de cloro para ser introduzida na cisterna, quando essa é abastecida. A pastilha é disposta no interior da cisterna sem uma avaliação da dosagem necessária em relação à quantidade de água armazenada e à sua qualidade.

No geral, as águas naturais possuem alcalinidade variando na faixa de 30 a $500 \mathrm{mg} / \mathrm{L}$ de $\mathrm{CaCO}_{3}$. Esse parâmetro, para as águas de consumo humano, não tem significado sanitário, embora possa apresentar sabor desagradável (BRASIL, 2006; PREFEIRA et al., 2010). Nos sistemas de abastecimento de água a alcalinidade mostra-se importante para os processos de coagulação e controle da corrosão já que possibilita neutralizar ácidos na água. Considerando apenas o abastecimento das cisternas por meio de água de chuva, em cerca de $43 \%$ das amostras a alcalinidade foi inferior a $50 \mathrm{mg} / \mathrm{L}$, enquanto águas de outras fontes (poço ou águas superficiais) foi de $26,2 \%$ (Tabela 1 ).

Os resultados da Tabela 1 evidenciaram que as águas das cisternas abastecidas com água de chuva possuíam teores de cloreto variando de 20 a $230 \mathrm{mg} / \mathrm{L}$, sendo que para as águas das cisternas que tinham como origem outras fontes, cerca de $73,2 \%$ das amostras apresentaram teores menores que $80 \mathrm{mg} / \mathrm{L}$ e nas águas de chuva esse percentual reduziu para 40,5\%. Quando se analisa todas as fontes de abastecimento das cisternas, constata-se que cerca de $25,5 \%$ das amostras possuíam teores de cloreto entre 90 a $130 \mathrm{mg} / \mathrm{L}$ e para cisternas abastecidas com águas de chuva $50,0 \%$. Não foi encontrado caso com valores acima do permitido pela Portaria $N^{\circ} 2914 / 2011$ do Ministério da Saúde $(250 \mathrm{mg} / \mathrm{L})$. No que se refere às águas de chuva era de se esperar a maioria das cisternas apresentassem teores baixos de cloreto, porém 59,5\% apresentaram valores de cloreto acima de $90 \mathrm{mg} / \mathrm{L}$. Esses resultados podem indicar que a água entrou em contato com resíduos, quer seja ao escoar pelo telhado, tubulações ou na própria cisterna em face do manuseio inadequado, como por exemplo, com a retirada de água com balde. Durante o levantamento de campo foi detectado que $92,75 \%$ da população utiliza balde para retirar a água da cisterna, justificando ser mais fácil. Porém dados levantados na pesquisa também mostrou que $17,23 \%$ da população não recebeu a bomba, 51,45\% das bombas encontravam-se quebradas ou com vazamento, e $31,32 \%$ das bombas estavam em bom estado. Os cloretos, quando encontrados nas águas subterrâneas são provenientes da dissolução de minerais ou intrusão de águas do mar e quando percebi dos nas águas superficiais normalmente decorrem de lançamento dos esgotos domésticos ou industriais em altas concentrações (SILVA, 2011). Segundo o autor ainda é conferido as águas com presença de cloreto um sabor salgado podendo essas águas também terem propriedades laxativas. 0 cloreto pode produzir danos às instalações metálicas e em estruturas de construção (BRASIL, 2006), e no caso das cisternas pode, em teores elevados, trazer prejuízos às estruturas de placas pré-moldadas de concreto, causando danos pelo processo corrosivo, mas não acontecem incrustações, pois o cloreto tem boa solubilidade em água (POHLING, 2009).

A dureza indica a presença de sais de cálcio e magnésio ou ainda metais bivalentes. Podem causar sabor desagradável na água, produzir efeitos laxativos e reduzir a formação da espuma de sabão (BRASIL, 2006). As amostras de água coletadas evidenciaram que o teor de dureza variou de 10 a $140 \mathrm{mg} / \mathrm{L}$, sendo que, apesar de estarem dentro dos padrões estabelecidos pela Portaria, as águas da chuvas apresentaram valores de dureza no intervalo de 60 a $100 \mathrm{mg} / \mathrm{L}$ maiores que as águas com origem em outras fontes (Tabela 1). Os valores encontrados estão muito abaixo do permitido pela Portaria MS No 2914/2011 (500mg/L).

A cor indica a presença de substâncias dissolvidas na água, podendo apresentar intensidades que variam de 0 a 200 unidades de Hazen, sendo de difícil percepção em valores inferiores a 10 uH. A prática da cloração de água com cor pode implicar na geração de produtos cancerígenos (a reação da matéria-orgânica com o cloro pode formar os trialometanos que são cancerígenos Portaria No 2914) (BRASIL, 2006), o que se constitui uma preocupação no caso particular dos sistemas de captação de água de chuva. Isso porque as cisternas estão susceptíveis à introdução de resíduos por diversos meios e a prática disseminada de cloração sem o devido cuidado e controle pode implicar na geração desses compostos. Pôde-se constatar que as amostras das cisternas abastecidas com água de chuva não apresentaram problemas com a cor aparente $(100,0 \%$ dos resultados com cor igual a $3 u \mathrm{H})$, e as águas de outras fontes, cerca de $83,1 \%$ e $16 \%$ das amostras com cor igual a $3 \mathrm{uH}$ e $5 \mathrm{uH}$ respectivamente (Tabela 1).

Os teores de ferro na água $(0,25 \mathrm{mg} / \mathrm{L})$, tanto das amostras de água de chuva como de outras fontes, evidenciaram condições próprias para consumo humano já que as amostras apresentaram valores máximos abaixo do permitido pelo Ministério da Saúde $(0,3 \mathrm{mg} / \mathrm{L})$. Somente um percentual pequeno $(3,3 \%)$ das águas com origem em outras fontes apresentaram problemas. Comportamento semelhante ocorreu com o parâmetro amônia: todas amostras coletadas para as águas de chuva apresentaram ausência deste parâmetro, e 80\% das águas com outras fonte. Conforme as recomendações recebidas pelos responsáveis pelas ações de educação sanitária do P1MC, conforme já foi explicitado, o morador recebe uma pastilha de cloro sempre que a cisterna é abastecida para realizar a desinfecção. Apesar de a 
população introduzir a pastilha sem controle em relação à quantidade da dosagem necessária, as águas analisadas não apresentaram inconformidade, segundo o estabelecido pela Portaria № 2914/2011 do Ministério da Saúde, quanto a este parâmetro. Segundo a Portaria, o valor máximo de $5 \mathrm{mg} / \mathrm{L}$ foi definido de forma a assegurar a aceitação organoléptica da água. Conforme os dados apresentados na Tabela 1, a maioria das águas estu- dadas apresentaram valores de cloro abaixo de $0,25 \mathrm{mg} / \mathrm{L}$.

Observando os resultados encontrados para o $\mathrm{pH}$, todas as águas encontravam-se dentro do padrões. 0 valor de referência para o parâmetro $\mathrm{pH}$ variou de 6,5 a 8,0, sendo que o valor máximo de 8,0 foi definido devido à eficiência da desinfecção por cloração em pH abaixo de 8,0.

Tabela 1 - Teores das características físico-químicas das análises das amostras de água coletadas nas cisternas dos domicípios estudados. Bahia, 2013-2015

Parâmetros físico químicos

Faixas
Cisternas abastecidas com todas as fontes de água $(\mathrm{N}=455)$
Cisternas abastecidas por água de chuva água $(\mathrm{N}=42)$

\begin{tabular}{cccc}
\hline \multirow{2}{*}{ Alcalinidade (mg/L) } & $10-50$ & $11(26,2 \%)$ & $197(43,0 \%)$ \\
& $60-80$ & $17(40,5 \%)$ & $140(31,0 \%)$ \\
& $90-110$ & $14(33,3 \%)$ & $118(26,0) \%$ \\
Cloreto (mg/L) & $10-80$ & $335(73,2 \%)$ & $17(40,5 \%)$ \\
& $90-130$ & $116(25,5 \%)$ & $21(50,0 \%)$ \\
& $140-230$ & $4(0,9 \%)$ & $4(9,5 \%)$ \\
Dureza (mg/L) & $10-50$ & $218(47,9 \%)$ & $31(73,8 \%)$ \\
& $60-100$ & $236(51,9 \%)$ & $1(2,4 \%)$ \\
Cor (uH) & $110-140$ & $1(0,2 \%)$ & $42(100,0 \%)$ \\
& 3 & $378-83,1 \%$ & \\
Ferro (mg/L) & 5 & $73(16,0 \%)$ & $42(100,0 \%)$ \\
& 15 & $1(0,2 \%)$ & $42(100,0 \%)$ \\
& 25 & $3(0,7 \%)$ & \\
Amônia (mg/L) & 0,25 & $440(96,7 \%)$ & $28(84,9 \%)$ \\
& 0,50 & $1(0,2 \%)$ & $5(15,2 \%)$ \\
Cloro (mg/L) & 1,00 & $14(3,1 \%)$ & $3(7,1 \%)$ \\
& $0,00-0,35$ & $364(80,0 \%)$ &
\end{tabular}

Fonte: Dos autores (2017)

Análise da qualidade das águas dos poços perfurados pela Cerb nos municípios estudados. Segundo dados da Cerb foram, até 2015, perfurados 434 poços nos municípios estudados, sendo 120 em Abaré, 87 em Chorrochó, 85 em Macururé, 37 em Glória e 105 em Santa Brígida. Dos poços perfurados somente 245 (56,5\%) apresentaram vazões aproveitáveis. Os poços secos ou com vazão insuficiente para utilização das águas somaram 35\%, e os demais enquadraram-se em outras categorias com menores percentuais (Figura 2).

Segundo os dados fornecidos pela Cerb (2015), in loco, os poços localizados nos municípios estudados, com vazões aproveitáveis, encontram-se em rochas com características cristalinas, sedimentares, meta sedimentares, xistos, quartzitos e filitos. Os tipos das rochas interferem nas características químicas das águas subterrâneas, quando estas percolam nos espaços vazios. Além de haver uma estreita relação entre as características das rochas e a composição química das águas, as atividades humanas também interferem na propriedade da água. Cada tipo de solo, em contato com a água, reflete características hidrogeoquímicas especificas, necessitando muitas vezes que a água sofra tratamento, antes de ser destinada ao consumo humano. Conforme citado por Brito, Pereira e Melo (2009), as águas subterrâneas encontradas em solos cristalinos têm probabilidade de serem salobras ou salgadas. Essa citação foi confirmada nos resultados da qualidade de água desse trabalho, quando aplicado o método Piper. 
Figura 2 - Características dos poços perfurados nos municípios estudados

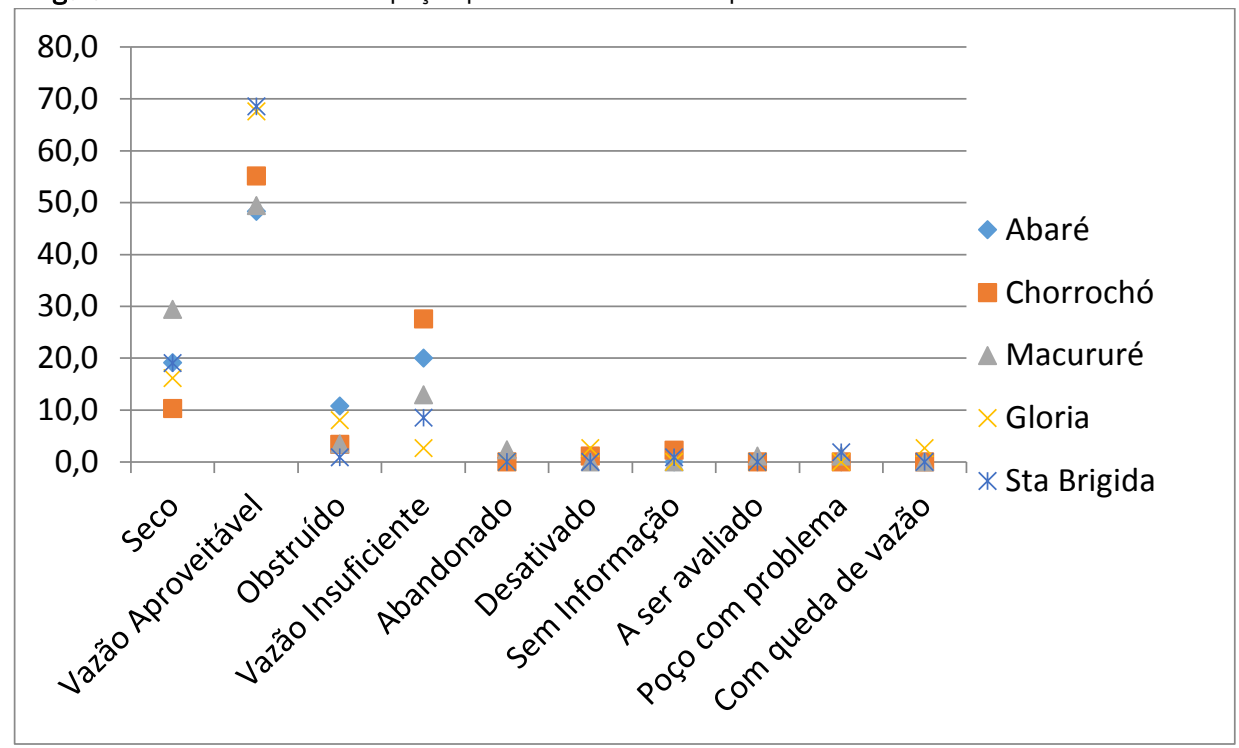

Fonte: Própria, a partir de dados da Cerb (2015)

Os dados encontrados são confirmados também por Oliveira et al. (2007), quando apresenta domínio do embasamento cristalino. Segundo os autores, esse tipo de solo está presente em cerca de $36 \%$ da área do Estado ocupando uma de $201.600 \mathrm{~km}^{2}$, e é composta essencialmente por granitos, gnaisses, migmatitos e granulitos. Ainda segundo os autores, essas rochas são formadas por aquíferos de natureza fissural, com reduzida potencialidade hídrica. Nesse domínio ainda pode ser encontrado dois subgrupos, que são classificados a partir da situação pluviométrica: subdomínio de pluviometria menor do que $800 \mathrm{~mm} / \mathrm{ano}$; e subdomínio de pluviometria maior do que $800 \mathrm{~mm} / a n o$. No subdomínio menor do que $800 \mathrm{~mm} / \mathrm{ano}$, onde estão localizados os municípios estudados, situam-se as áreas de maior déficit hídrico do Estado e com maior aridez, devido a baixa capacidade de armazenamento das rochas e do elevado índice de evaporação (OLIVEIRA et al. (2007). Os efeitos disso implicam em baixa produção dos poços e também maior índice de salinidade das águas (GUERRA e NEGRÃO, 1996).

Dos poços perfurados em Abaré, que encontram-se com vazão aproveitável, 98,4\% deles estão localizados no cristalino e 1,6\% no calcário. Chorrochó tem $12 \%$ dos poços com vazão aproveitável em solo do tipo xisto, $2 \%$ meta-sedimentar e $86 \%$ em solo cristalino. Macururé tem 2,5\% dos poços com vazão aproveitável em solo do tipo xisto, 2,5\% filito, $12,5 \%$ sedimentar, $2,5 \%$ metasedimentar e $80 \%$ em solo cristalino. Glória tem $50 \%$ dos poços com vazão aproveitável em solo do tipo sedimentar, 4,2\% metasedimentar e 45,8\% em solo cristalino. Santa Brígida tem 23,3\% dos poços com vazão aproveitável em solo do tipo sedimentar,
$12,2 \%$ meta-sedimentar, quartzito 1,3\% e $63 \%$ em solo cristalino. Essas informações são confirmadas nos estudos de Vieira e Joaquim Filho (2006), quando diagnosticaram a situação geológica do sertão, estando $70 \%$ dos solos em área cristalina, com solos rasos e pedregosos, baixa capacidade de infiltração e de retenção de água, apresentando forte salinização.

Esses resultados foram confirmados com a análise de água feita em um poço localizado no município de Macururé perfurado pela Cerb. Quando analisado os parâmetros físico-químicos, para o parâmetro cloreto foi encontrado valor acima de $2000 \mathrm{mg} / \mathrm{L}$. (Trabalho de campo feito no dia 5 de março de 2016).

A condutividade elétrica é a capacidade de uma substância conduzir a corrente elétrica e está diretamente ligada ao teor de sais dissolvidos sob a forma de íons (MME, 2005). A medida de condutividade elétrica, multiplicada por um fator que varia entre 0,55 e 0,75, fornece uma boa estimativa de teor de sais dissolvidos (STD) na água subterrânea. Segundo o padrão de potabilidade da Organização Mundial da Saúde (OMS), o limite máximo permissivel de STD na água é de $1.000 \mathrm{mg} / \mathrm{L}$. Valores elevados da condutividade elétrica indicam que a água tem sabor desagradável, vindo a causar problemas digestivos. A Tabela 2 apresenta a classificação das águas dos poços perfurados nos municípios segundo os intervalos de STD, constata-se que 35,36\% das amostras de água dos poços perfurados pela Cerb são classificados como salina e $38,21 \%$ salobra. A análise da condutividade elétrica realizada adotou um fator de 0,55. 
Tabela 2 - Percentual do STD das águas dos poços perfurados pela Cerb nos municípios estudados

\begin{tabular}{cccc}
\hline Municípios & STD $>1000$ & STD>500 & STD>1500 \\
\hline Total & 38,21 & 47,15 & 35,36 \\
Abaré & 59,64 & 70,17 & 59,65 \\
Chorrochó & 46,93 & 53,06 & 42,86 \\
Macururé & 34,14 & 31,70 & 24,39 \\
Glória & 4,00 & 8,00 & 4,00 \\
Santa Brígida & 29,73 & 43,24 & 24,32 \\
\hline
\end{tabular}

Fonte: Própria (2017)

A resolução Conama $n^{\circ} 357$ de 2005 define que para água doce o máximo valor permitido é de $500 \mathrm{mg} / \mathrm{L}$ de sólidos totais dissolvidos.

Os resultados das análises das águas do poço, em função da sua origem ser subterrânea, foram comparadas aos valores limites estabelecidos na Resolução Conama No 396/2008. Os valores máximos permitidos (VMP) para os limites de detecção foram das águas classe 1. Isso se deveu ao fato dessa água fazer parte do conjunto de aquíferos ou porção desses, sem alteração de sua qualidade por atividades antrópicas, e que não exigem tratamento para quaisquer usos preponderantes devido às suas características hidrogeoquimicas naturais.
Glória foi o município que mais apresentou poços com águas atendendo ao exigido para classe 1, diferindo de Abaré, com maiores percentuais de poços que estiveram com valores dos parâmetros acima do proposto. Nitrito foi o parâmetro no qual todas as águas dos poços atenderam as especificações. Esses valores demonstram a relação da qualidade da água na presença de solo cristalino (Tabela 3).

No Brasil, as legislações existentes não apresentam um limite máximo para a condutividade elétrica de forma a avaliá-la como aceitável, contudo seus valores podem expressar contaminação por efluentes industriais (LÔNDERO; GARCIA, 2010). Resultados que indicam contaminação devido à presença de esgotos, po-

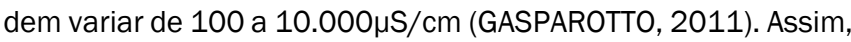
esse trabalho considerou um valor aceitável de $100 \mu \mathrm{S} / \mathrm{cm}$.

Tabela 3 - Percentual das amostras de água dos poços perfurados pela Cerb que não atenderam ao VMP estabelecido pela Conama №. $396 / 2008$ nos municípios estudados

\begin{tabular}{|c|c|c|c|c|c|c|c|}
\hline \multicolumn{2}{|c|}{ Parâmetros analisados } & \multirow{2}{*}{$\begin{array}{c}\text { VMP* } \\
1000 \mathrm{mg} / \mathrm{l}\end{array}$} & \multirow{2}{*}{$\begin{array}{l}\text { Abaré } \\
93,1\end{array}$} & \multirow{2}{*}{$\begin{array}{r}\text { Chorrochó } \\
65,3\end{array}$} & \multirow{2}{*}{$\begin{array}{r}\text { Macururé } \\
46,3\end{array}$} & \multirow{2}{*}{$\begin{array}{r}\text { Glória } \\
12,0\end{array}$} & \multirow{2}{*}{$\begin{array}{r}\text { Santa Brígida } \\
45,9\end{array}$} \\
\hline STD & $(\mathrm{mg} / \mathrm{l})$ & & & & & & \\
\hline Cloreto & $(\mathrm{mg} / \mathrm{l} \mathrm{Cl})$ & $250 \mathrm{mg} / \mathrm{l}$ & 94,8 & 67,3 & 46,3 & 12,0 & 52,7 \\
\hline Nitrato & (mg/l N-NO3) & $10 \mathrm{mg} / \mathrm{l}$ & 29,3 & 14,3 & 17,1 & 8,0 & 9,5 \\
\hline Ferro & (mg/l Fe) & $0,3 \mathrm{mg} / \mathrm{I}$ & 3,4 & 4,1 & 9,8 & 4,0 & 13,5 \\
\hline Fluoreto & $(\mathrm{mg} / \mathrm{l} F)$ & $1,5 \mathrm{mg} / \mathrm{I}$ & 24,1 & 16,3 & 12,2 & 4,0 & 1,4 \\
\hline Nitrito & $\left(\mathrm{mg} / \mathrm{I} \mathrm{N}-\mathrm{NO}_{2}\right)$ & $1 \mathrm{mg} / \mathrm{l}$ & 0,0 & 0,0 & 0,0 & 0,0 & 0,0 \\
\hline Sulfato & $\left(\mathrm{mg} / \mathrm{ISO}_{4}\right)$ & $250 \mathrm{mg} / \mathrm{l}$ & 19,0 & 18,4 & 22,0 & 4,0 & 10,8 \\
\hline Sódio & $(\mathrm{mg} / \mathrm{l})$ & 200mg/l & 41,4 & 20,4 & 14,6 & 0,0 & 18,9 \\
\hline Condutividade & $(\mu \mathrm{S} / \mathrm{cm})$ & - & 100,0 & 100,0 & 100,0 & 100,0 & 100,0 \\
\hline
\end{tabular}

* - 0 VMP foi estabelecido pela Resolução Conama n ${ }^{\circ} 396 / 2008$

Fonte: Própria. (Dados fornecidos pela Cerb em maio de 2015)

A Figura 3 apresenta a plotagem das proporções dos cátions principais $\left(\mathrm{Ca}^{+2}, \mathrm{Mg}^{+2}, \mathrm{Na}^{+2} \mathrm{e} \mathrm{K}^{+}\right)$e dos ânions principais ( $\mathrm{HCO}_{-3}, \mathrm{Cl}^{-} \mathrm{e}$ $\mathrm{SO}_{4}^{-2}$ ) e a combinação de informações dos dois triângulos no losango situado entre os mesmos.
Todos os resultados encontrados indicaram o que já foi apresentado na literatura, a exemplo do estudo desenvolvido por Nanes et al. (2012) no município de São Sebastião - AL. 
Figura 3 - Diagrama de Piper para avaliação da qualidade das águas dos poços da Cerb localizados nos municípios estudados

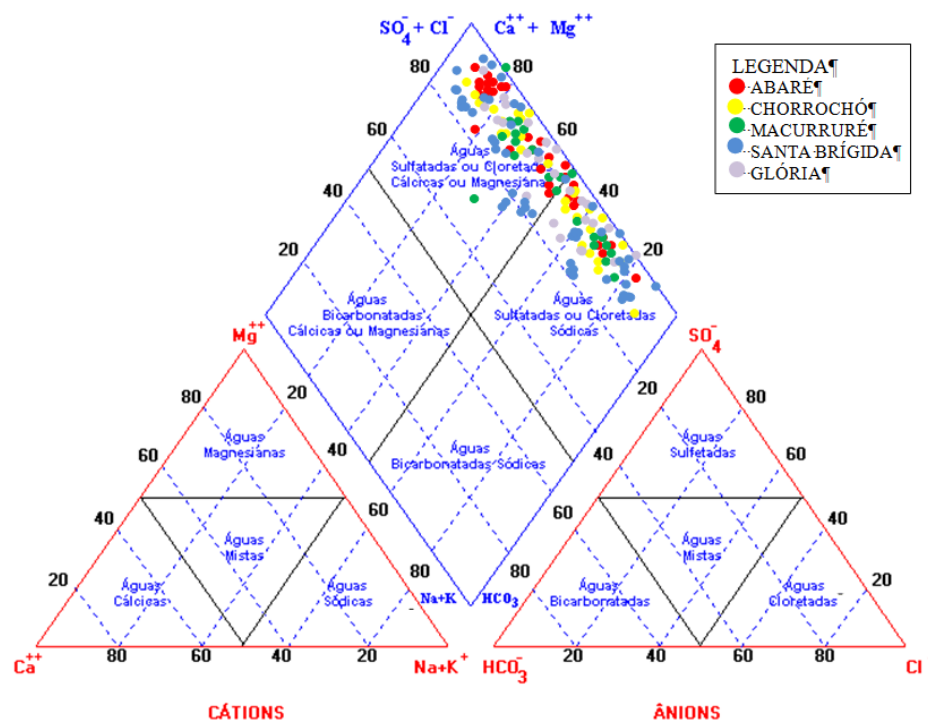

Fonte: Própria (2017)

As águas estudadas para o município de Abaré foram caracterizadas como sulfatadas ou cloradas cálcicas ou magnesianas $(65,7 \%)$ e água sulfatada ou cloretada sódica (34,3\%). Fazendo um paralelo entre as características das rocha encontradas no município e o tipo de água quanto à sua composição química, pode-se concluir que as águas não diferenciam dos dados já apresentados na literatura (SANTOS 2012; BRITO; PREREIRA; MELO, 2009), com tendência à salinização. 0 município de Chorrochó apresenta a maior parte do seu território com rocha cristalina. A presença das rochas cristalinas pode ser evidenciada na qualidade das águas dos poços da Cerb. Os resultados iônicos evidenciaram águas sulfatadas ou cloradas cálcicas ou magnesianas (50\%) e água sulfatada ou cloretada sódica (50\%). 0 município de Macururé apresenta a maior parte do seu território com rocha cristalina (80\%). A presença da rocha cristalina influenciou na característica das águas dos poços da Cerb, que quando avaliadas pelo método Piper, apresentaram-se como águas sulfatadas ou cloradas cálcicas ou magnesianas (65\%) e água sulfatada ou cloretada sódica (35\%). Avaliando os resultados encontrados na Portaria № 2914/2011 do Ministério da Saúde, todas as águas dos poços não atendem às exigências para o abastecimento de água para consumo humano.

\section{CONCLUSÃO}

O estudo revela a vulnerabilidade da população do semiárido baiano, na região estudada, quanto ao acesso à água, em especial à qualidade para o consumo humano. Os resultados evidenciaram que não existe um controle na qualidade das águas consumidas, e que existem parâmetros que estão acima do máximo permitido pela Portaria $n^{\circ} 2914$ de 2011 do Ministério da Saúde, quanto à potabilidade, necessitando de tratamento posterior.

As águas provenientes dos carros-pipa apesar de a maioria apresentar os valores referentes aos parâmetros físico-quimicos dentro dos limites permitidos pela Portaria n 2914 o Ministério da Saúde, algumas amostras encontravam-se fora do limite permitido. Essas águas ainda apresentaram vulnerabilidade antrópica devido ao manuseio da água inadequado e uso de cloro atender as proporções adequadas.
No que se refere às águas subterrâneas, proveniente dos poços perfurados pela Cerb, uma vez que os municípios onde os poços foram perfurados enco...ram-se em solo cristalino e sedimentar na sua maioria, suas águas tendem a ser salgadas, com características sulfatadas ou cloradas cálcicas ou magnesianas e água sulfatada ou cloretada sódica. Outros fatores também influenciam para o surgimento desse tipo de água, como irrigação com volumes errados, associada ao tipo de solo e a evaporação das águas. Os resultados encontrados também indicam que as águas dos poços precisam de tratamento para serem utilizadas para abastecimento humano.

No que se refere às águas de chuva presentes nas cisternas estudadas, constatou-se que estas atenderam aos padrões de potabilidade quanto aos parâmetros físico-químicos da Portaria № 2914/2011.

Os resultados encontrados para as águas superficiais referiramse a um momento específico de medição, estando a maioria dos parâmetros atendendo a Portaria ${ }^{\circ} 2914$ de 2011 do Ministério da Saúde. Porém não existe um acompanhamento por parte do poder público quanto à qualidade de água consumida pelas populações beneficiadas pelo $\mathrm{P} 1 \mathrm{MC}$, nem tão pouco foi detectado durante o levantamento de campo, que o sistema de captação e armazenamento de água de chuva fornecido contemple separador das primeiras águas de chuva, e filtros (que deveriam ser instalados após o separador das primeiras águas). A ausência do acompanhamento e dos equipamentos citados pode acarretar em variação da qualidade de uma água para outra no interior da cisterna. Assim, esse trabalho recomenda que haja uma participação continuada do poder público e que sejam adaptados equipamentos que venham contribuir para melhor qualidade da água, já que seu uso é destinado ao consumo humano.

\section{REFERÊNCIAS}

ARTICULAÇÃO NO SEMIÁRIDO BRASILEIRO. Programa de formação e mobilização social para a convivência com o semiárido: um milhão de cisternas rurais - P1MC. Recife: ASA, 2002. 
ARTICULAÇÃO NO SEMIÁRIDO BRASILEIRO. Ações do P1MC. http://www.asabrasil.org.br/acoes/p1mc\#categoria_img (acesso em juIho 2017).

BARBOSA, D. V. N. Os impactos da seca de 1993 no semiárido Baiano: caso de Irecê. Salvador: SEI, Série estudos e pesquisa, 51. 2000.

BORJA P. C. Qualidade da água distribuída e consumida pela população da cidade do salvador: características e fatores determinantes. I-20. In: SIMPÓSIO ÍTALO BRASILEIRO DE ENGENHARIA SANITÁRIA E AMBIENTAL, 6., 2002. Anais... Vitória-ES, 2002.

BRASIL. Vigilância e controle da qualidade da água para consumo humano. Brasília: Ministério da Saúde. Secretaria de Vigilância em Saúde., 2006.

BRASIL. Desertificação: caracterização e impactos. Brasília: Ministério do Meio Ambiente, dos Recursos Hídricos e da Amazônia Legal. 1999.

BRITO L. T. L., PEREIRA L. A. e MELO R. F. de. Disponibilidade hídrica subterrânea. Agência Embrapa de Informação Tecnológica, 2009.

COMPANHIA DE ENGENHARIA HÍDRICA E DE SANEAMENTO DA BAHIA. Base de dados sobre a qualidade da água dos poços perfurados no estado da Bahia. Salvador, 2015.

EIRÓ, F.; LINDOSO D. Peinvenção de práticas clientelistas no Programa Um Milhão de Cisternas - P1MC. Ciência e Sustentabilidade - CeS. v. 1, n. 1, p. 62-76, jul/dez 2015

GASPAROTTO, F. A. Avaliação ecotoxicológica e microbiológica da água de nascentes urbanas no município de Piracicaba-SP. Universidade de São Paulo. Piracicaba, p. 90. 2011.

GUERRA, A. M.; NEGRÃO, F. I. Domínios Hidrogeológicos do Estado da Bahia. In: CONGRESSO BRASILEIRO DE ÁGUAS SUBTERRÂNEAS, 10. 1996. Anais... Salvador-Bahia. 1996.

LÔNDERO, E.; GARCIA, C. S. Site Higienistas, 2010. (Acesso em: 24 Outubro 2014.)

LORDELO L. M. K. BORJA P. C., PORSANI M. J., MORAES L. R. S., ORRICO S. R. Magalhães. Avaliação do uso e funcionamento das cisternas do $\mathrm{P} 1 \mathrm{MC}$ - um estudo no semiárido baiano. Revista Eletrônica de Gestão e Tecnologias Ambientais. (Aprovado, mas não publicado)

MASQUETTO G. B.; SILVA H. V. Uso do diagrama de piper para classificação de águas subterrâneas ao município de Maringá-PR. In: EPCC - ENCONTRO INTERNACIONAL DE PRODUÇÃO CIENTÍFICA CESUMAR, 8., 2013. Anais.... Maringá - Paraná. 2013.

MELO FILHO, J. F. de, SOUZA, A. L. V. O manejo e a conservação do solo no Semiárido baiano: desafios para a sustentabilidade. Bahia Agríc., v.7, n.3, nov. 2006
MOLION, L. C. B. BERNARDO, S. O. Dinâmica das chuvas sobre o Nordeste do Brasil, In: CONGRESSO BRASILEIRO DE METEOROLOGIA, 11., 2000. Anais... CL00132, Rio de Janeiro. 2000.

NANES P. L. M. de F., NANES D. P., FARIAS S. E. M. de. Qualidade das águas subterrâneas de poços tipo cacimba: um estudo de caso da comunidade nascença - município de São Sebastião - AL. In: CONGRESSO BRASILEIRO DE GESTÃO AMBIENTAL GOIÂNIA/GO, 3., 2012. Anais... Goiânia, 2012.

OLIVEIRA I. B. de, NEGRÃO F. I. SILVA A. G. L. S. Mapeamento dos aquíferos do estado da Bahia utilizando o índice de qualidade natural das águas subterrâneas - IQNAS. Águas Subterrâneas, v.21, n.1, p.123-137, 2007.

OLIVEIRA, M. Gênese, classificação e extensão de solos afetados por sais. In: CONGRESSO BRASILEIRO DE ENGENHARIA AGRÍCOLA, 26, 1997, Campina Grande. Anais..., Campina Grande, PB: UFPB, SBEA, p. 1-35, 1997.

PEREIRA S. de F. Pi., COSTA A. de C., CARDOSO E. do S. C., CORRÊA M. do S. S., ALVES D. T. V., MIRANDA R. G., OLIVEIRA G. R. F. de. Condições de potabilidade da água consumida pela população de abaetetuba-Pará. Revista de estudos ambientais (Online). n. 1, v.12, p. 50-62, jan./jun. 2010 Disponivel em: <http://proxy.furb.br/ojs/index.php/rea/article/view/1783>. Acesso em: 25 fev. 2017.

PIPER, A.M. A graphic procedure in the geochemical interpretation of water analyses. Am. Geophysics Union Trans., v. 25, p. 914 - 923, 1944.

POHLING, R. Reações químicas na análise de água. Fortaleza: Gráfica Editora Arte Visual. 2009.

RAMALHO M. F. de J. L. A fragilidade ambiental do Nordeste brasileiro: clima semiárido e as imprevisões das grandes estiagens. Sociedade e Território, Natal, v. 25, n. 2, edição especial, p. 104-115, jul./dez. 2013.

SANTOS N. M. de S. S. Salinidade da água na adaptabilidade de ovinos e respectivos dejetos no crescimento de plântulas de milho. Trabalho apresentado a Universidade Federal do Vale do São Francisco - UNIVASF, campus Ciências Agrárias, como requisito da obtenção do título de Mestre em Ciência Animal. Petrolina-PE, 2012.

SILVA Í. N. Agropecuária Científica no Semiárido, UFCG - Patos - PB. ACSA - Agropecuária Científica no Semiárido, v.07, n 03, p. 01 - 15 jul./set. 2011.

VASCONCELOS O. C. de M.; MATOS C. H. L. de; PRADO R. J. do; SOUZA F. G. de; LOPES A. D. O. Recuperação de planossolos Nátricos Salinos em Juazeiro-BA através do cultivo de espécies nativas da caatinga. In: Congresso Brasileiro de Reflorestamento Ambiental , 2., 2012. Anais... Guarapari - ES: SESC Centro de Turismo de Guarapari, 2012.

ZAPOROZEC, A. Graphical Interpretation of Water-Quality Data, v. 10, n. 2 - Ground Water April, 1972. 